\title{
Putative DNA G-quadruplex formation within the promoters of Plasmodium falciparum var genes
} Nicolas Smargiasso*†1, Valérie Gabelica ${ }^{1}$, Christian Damblon², Frédéric Rosu ${ }^{1}$, Edwin De Pauw ${ }^{1}$, Marie-Paule Teulade-Fichou ${ }^{3}$, $\mathrm{J}_{\text {Alexandra Rowe }}{ }^{4}$ and Antoine Claessens ${ }^{\dagger 4}$

Address: ${ }^{1}$ Mass Spectrometry Laboratory, GIGA-Research, University of Liege, Liege, Belgium, ${ }^{2}$ Structural Biological Chemistry Laboratory, University of Liege, Liege, Belgium, ${ }^{3}$ Institut Curie, Section Recherche, CNRS UMR176, Centre Universitaire Paris XI, Bat. 110, 91405 Orsay, France and ${ }^{4}$ Centre for Immunity, Infection and Evolution, Institute of Immunology and Infection Research, School of Biological Sciences, University of Edinburgh, Edinburgh, UK

Email: Nicolas Smargiasso* - nsmargiasso@ulg.ac.be; Valérie Gabelica - V.Gabelica@ulg.ac.be; Christian Damblon - c.damblon@ulg.ac.be; Frédéric Rosu - F.Rosu@ulg.ac.be; Edwin De Pauw -E.DePauw@ulg.ac.be; Marie-Paule Teulade-Fichou - marie-paule.teulade-fichou@curie.fr; J Alexandra Rowe - Alex.Rowe@ed.ac.uk; Antoine Claessens - a.j.a.h.claessens@sms.ed.ac.uk

* Corresponding author †Equal contributors

Published: 6 August 2009

BMC Genomics 2009, 10:362 doi:10.1/86/147|-2164-10-362
Received: 28 July 2008

Accepted: 6 August 2009

This article is available from: http://www.biomedcentral.com/147I-2/64/10/362

(c) 2009 Smargiasso et al; licensee BioMed Central Ltd.

This is an Open Access article distributed under the terms of the Creative Commons Attribution License (http://creativecommons.org/licenses/by/2.0), which permits unrestricted use, distribution, and reproduction in any medium, provided the original work is properly cited.

\begin{abstract}
Background: Guanine-rich nucleic acid sequences are capable of folding into an intramolecular four-stranded structure called a G-quadruplex. When found in gene promoter regions, Gquadruplexes can downregulate gene expression, possibly by blocking the transcriptional machinery. Here we have used a genome-wide bioinformatic approach to identify Putative GQuadruplex Sequences (PQS) in the Plasmodium falciparum genome, along with biophysical techniques to examine the physiological stability of $P$. falciparum $P Q S$ in vitro.

Results: We identified $63 \mathrm{PQS}$ in the non-telomeric regions of the $P$. falciparum clone 3D7. Interestingly, 16 of these PQS occurred in the upstream region of a subset of the P. falciparum var genes (group B var genes). The var gene family encodes PfEMPI, the parasite's major variant antigen and adhesin expressed at the surface of infected erythrocytes, that plays a key role in malaria pathogenesis and immune evasion. The ability of the PQS found in the upstream regions of group $B$ var genes (UpsB-Q) to form stable G-quadruplex structures in vitro was confirmed using ' $H$ NMR, circular dichroism, UV spectroscopy, and thermal denaturation experiments. Moreover, the synthetic compound BOQI that shows a higher affinity for DNA forming quadruplex rather than duplex structures was found to bind with high affinity to the UpsB-Q.

Conclusion: This is the first demonstration of non-telomeric PQS in the genome of $P$. falciparum that form stable G-quadruplexes under physiological conditions in vitro. These results allow the generation of a novel hypothesis that the G-quadruplex sequences in the upstream regions of var genes have the potential to play a role in the transcriptional control of this major virulenceassociated multi-gene family.
\end{abstract}




\section{Background}

Plasmodium falciparum is responsible for the majority of malaria cases worldwide and is the cause of an estimated 300-500 million infections and 1-2 million deaths per year [1]. The parasite invades circulating red blood cells and causes them to adhere to microvascular endothelial cells and sequester in blood microvessels, leading to vascular obstruction. The only proteins known to be responsible for this cytoadherence are members of the $P$. falciparum erythrocyte membrane protein one (PfEMP1) family (reviewed in [2]). These highly polymorphic parasite-derived erythrocyte surface proteins are encoded by a repertoire of 50 to 60 var genes. Crucially, each parasite expresses only one var gene at a time, with transcription sometimes being switched to a different var gene in subsequent generations, so allowing antigenic variation and immune evasion [2].

Despite their extreme sequence variability in the coding regions, var genes can be divided into 3 major groups ( $A$, $\mathrm{B}$ and $\mathrm{C}$ ) according to the presence of one of three conserved 5' upstream (Ups) sequences (UpsA, UpsB and UpsC) [3]. Their chromosomal position further subdivides them into centromeric $(\mathrm{C})$ or telomeric $(\mathrm{T})$ locations [4]. Var gene groups have functional and clinical significance. For example, group $\mathrm{B}$ and $\mathrm{C}$ var genes are known to bind to the endothelial receptor CD36 [2], whereas group A var genes have been linked to the most severe clinical forms of malaria $[5,6]$.

The mechanisms regulating var gene transcription are not well understood and are currently the subject of intensive investigations. Var gene expression is thought to be regulated at the level of transcription initiation [7]. Many mechanisms have been suggested as being involved in the silencing of non-transcribed var genes including var intron sequences [8] and SPE and CPE motifs located in UpsB and UpsC sequences respectively $[9,10]$. The histone deacetylase PfSir2 is thought to be required for chromatin silencing in the subtelomeric regions [11], and histone methylation in the 5 ' Ups region has been shown to regulate transcription of the var2csa gene [12]. Finally, a var-specific subnuclear expression site has been proposed recently [13]. How these pieces of evidence fit together is still unclear, and other mechanisms may be discovered before the full picture of var gene transcriptional control is obtained.

DNA usually maintains a double helix structure, however, recent evidence shows that in guanine-rich regions, DNA can adopt a more complex structure called a G-quadruplex [14] (Figure 1). G-quadruplexes are composed by the stacking of guanine tetrads, each one being stabilized by 8 Hoogsteen Hydrogen bonds (Figure 1A). Consequently, sequences containing four groups of three guanines are theoretically able to fold into a G-quadruplex containing three guanine tetrads (Figure $1 \mathrm{~B}$ ). Although there are also a few examples of G-quadruplexes formed from two guanine tetrads [15], these are much less stable and thus less likely to occur in vivo [16]. Hence, as in previous genomewide analyses of potential G-quadruplex-forming sequences $[17,18]$, we chose to investigate here sequences containing at least three tracks of four guanines.

G-quadruplexes are also stabilized by interactions with cations located between the tetrads, at the center of the structure. Potassium and sodium are the most commonly described G-quadruplex stabilizing cations, although ammonium and strontium can also assume this function [19-22]. It was previously reported that there are about 376,000 potential G-quadruplex structures in the human genome $[17,18]$, and about $40 \%$ of human genes contain a putative G-quadruplex in their promoter [23]. Initial reports indicate a possible role for G-quadruplex sequences in the regulation of telomere length $[24,25]$ and the transcriptional regulation of several genes such as $c$-MYC, c-kit, or KRAS [23,26-32]. For example, in the case of the $c-M Y C$ proto-oncogene, a single nucleotide mutation that destabilizes the G-quadruplex structure in the promoter region leads to a three-fold increase in basal transcription levels, suggesting that the G-quadruplex acts as a transcriptional repressor element [27]. Furthermore, a small ligand that binds to and stabilizes the G-quadruplex structure was shown to suppress further $c-M Y C$ transcriptional activity [27].

Given the increasing evidence for the importance of Gquadruplex sequences in gene regulation, we decided to investigate whether G-quadruplexes could be discovered in the genome of $P$. falciparum, and in particular to determine whether there are any G-quadruplex sequences in the upstream regions of var genes that have the potential to play a role in the transcriptional control of this major virulence-associated multi-gene family. In addition, the ability of potential G-quadruplex sequences from $P$. falciparum to form stable G-quadruplex structures under physiological conditions was examined using biophysical techniques.

\section{Results and discussion Identification of putative G-quadruplex forming sequences in the $\mathbf{P}$. falciparum genome}

The genome of $P$. falciparum clone 3D7 was searched for Putative Quadruplex Sequences (PQS) using QGRS-Mapper [33] on both the positive and negative strands. We set up the QGRS-mapper software to identify all PQS with four repeats of at least three guanines interrupted by loops of a maximum length of 11 nucleotides. As expected, most PQS were found in the telomeres ( 828 out of 891 ) due to their repetitive sequence: GGGTT(T/C)A (see Additional 

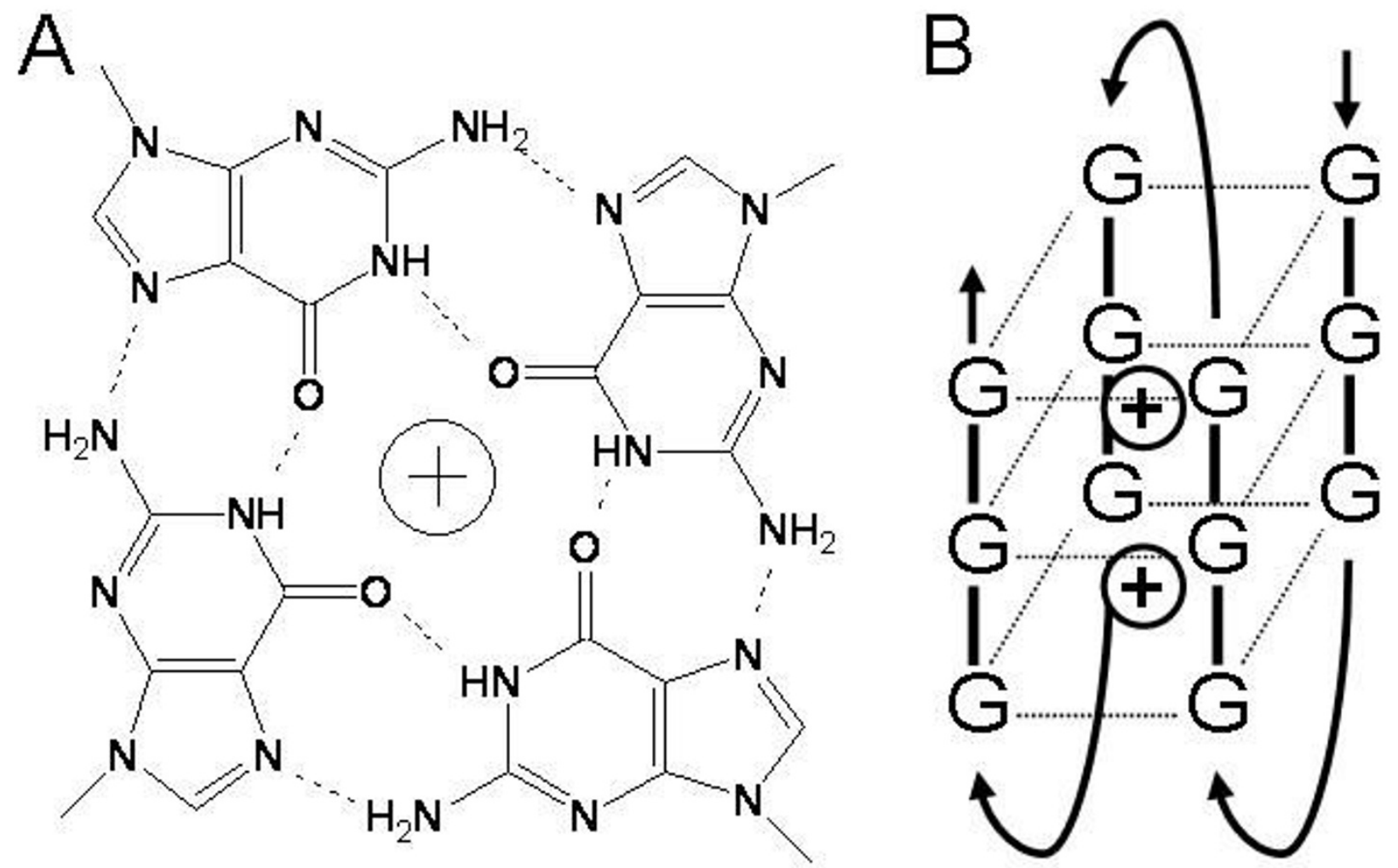

Figure I

(A) Chemical structure of a Guanine tetrad. (B) Schematic representations of a G-quadruplex formed by the folding of a G-rich strand.

file 1). These telomeric G-quadruplexes of $P$. falciparum have recently been described by De Cian et al [34]. Here we focused on the non-telomeric PQS because of their potential role in gene transcriptional regulation. We identified 63 non-telomeric PQS (listed in full in Additional file 2). This is an average of one PQS per $380 \mathrm{~kb}$, which is a much lower ratio than that seen in the human genome (1 PQS per $\sim 8 \mathrm{~kb}$ ) [17]. This was expected due to the extreme AT-richness $(80.6 \%)$ of the $P$. falciparum genome [35]. 37 of the 63 PQS are in intergenic regions, and of the 26 PQS within genes, 9 are on the coding strand and 17 on the non-coding strand.

\section{PQS in the upstreamB region of var genes}

Most importantly, 16 out of the 63 PQS were found in the upstreamB regions of var genes, 1612 to $1707 \mathrm{bp}$ upstream of the initiation codon (Table 1 and Additional file 2). These 16 PQS contain only three distinct sequences that thus represent three slightly different putative Gquadruplexes that we named UpsB-Q-1, UpsB-Q-2 and UpsB-Q-3 in order of their frequency (sequences shown in Table 2). As the var gene repertoire varies from one clone to another, we also searched for PQS in the upstream regions of var genes in $P$. falciparum clone HB3 (available from the Broad Institute website, http:// www.broad.mit.edu). Using the same parameters, we found 11 PQS in the upstream $\mathrm{B}$ region of var genes in HB3 (Table 1). Interestingly, UpsB-Q-1 was also the most common PQS (7 out of 11) in parasite clone HB3. One PQS was found in HB3 but not in 3D7 (named UpsB-Q4 , Table 1 and 2). These four types of PQS do not exist in any other sequenced organism to date (BLAST analysis, data not shown).

\section{Evidence of G-quadruplex formation by PQS in the upstream $B$ region of var genes}

In order to confirm the formation of G-quadruplexes by these sequences, two of them (UpsB-Q-1 and 2) were analyzed by ${ }^{1} \mathrm{H}$ NMR in the presence of ammonium or potassium ions. Using this technique, it is well established that the presence of imino protons with a chemical shift between 10 and $12 \mathrm{ppm}$ is characteristic of the formation of G-quadruplexes [36-38]. Spectra recorded on the presumably unstructured oligonucleotides in water did not show signals beyond 9 ppm, indicating that imino protons are in fast exchange with bulk water. The spectra 
Table I: Predicted G-quadruplex sequences in the upstream regions of Group B var genes from P. falciparum clones 3D7 and HB3

\begin{tabular}{|c|c|c|c|c|c|}
\hline \multicolumn{3}{|c|}{ P. falciparum clone 3D7 } & \multicolumn{3}{|c|}{ P. falciparum clone HB3 } \\
\hline Gene ID' & var group ${ }^{2}$ & PQS $^{3}$ & Gene ID 4 & var group ${ }^{2}$ & PQS $^{3}$ \\
\hline PF07_0139 & BT & Q-I & $\operatorname{varl4}$ & BT & Q-I \\
\hline PF08_0142 & BT & Q-I & $\operatorname{varl} 2$ & BT & Q-I \\
\hline PFII_0007 & BT & Q-I & $\operatorname{var} 13$ & BT & Q-I \\
\hline PFI3_0364 & BT & Q-I & $\operatorname{var} 20$ & BT & Q-I \\
\hline PFA0765c & BT & Q-1 & $\operatorname{var} 10$ & BT & Q-I \\
\hline PFBI055c & BT & Q-I & $\operatorname{var} 48 \psi$ & BT & Q-I \\
\hline PFC0005w & BT & Q-1 & $\operatorname{var} 49 \psi$ & BT & Q-I \\
\hline PFCII20c & BT & Q-1 & $\operatorname{var} 16$ & BT & Q-3 \\
\hline PFFI595c & BT & Q-I & $\operatorname{var} 15$ & BT & Q-3 \\
\hline PFI0005w & BT & Q-I & var8 & BT & $\mathrm{Q}-3$ \\
\hline MAL7PI.2I 2 & BT & Q-I & $\operatorname{var} 19$ & $\mathrm{BC}$ & $\mathrm{Q}-4$ \\
\hline MAL8PI.220 & BT & Q-1 & & & \\
\hline PFI0_0406 & BT & Q-2 & & & \\
\hline PFDI $245 c$ & BT & Q-2 & & & \\
\hline PFL0935c & $B C$ & Q-2 & & & \\
\hline PFA0005w & BT & Q-3 & & & \\
\hline
\end{tabular}

I According to PlasmoDB 5.4 http://plasmodb.org.

$2 \operatorname{Var}$ group: $B(T / C)=$ var gene with an upstream region $B$ located in telomeric $(T)$ or centromeric $(C)$ region. $\psi=$ pseudogene. [4]

3 PQS: putative quadruplex sequence. The PQS in the upstream B (UpsB) regions were named UpsB-Q-I, UpsB-Q-2 and UpsB-Q-3 in order of their frequency. A $4^{\text {th }} \mathrm{PQS}$ found only in $\mathrm{HB} 3$ was named UpsB-Q-4.

${ }^{4}$ According to Kraemer et al [4]

recorded after the addition of $150 \mathrm{mM}$ cation are presented in Figure 2 and show clearly the presence of imino protons for the four samples. Most importantly, for UpsBQ1 in ammonium and potassium, 11 imino peaks are clearly distinguished. In potassium, the peak at 11.93 ppm was resolved in two different peaks at $37^{\circ} \mathrm{C}$ (data not shown), indicating the formation of a single stable structure containing three quartets. In ammonium, the intensity of the peak at $11.55 \mathrm{ppm}$ could also indicate a superposition of two different peaks. On the UpsB-Q-2 spectra, the imino peaks are less well resolved, indicating some structural polymorphism. Moreover, in both PQS sequences, peaks were observed at higher chemical shift, indicating the possible presence of additional structures like AT-rich hairpins on these G-quadruplexes. These NMR data show that UpsB-Q1 and UpsB-Q-2 do form stable G-quadruplex structures in the presence of physiological concentrations of potassium ions.

The four types of PQS found in the upstream B regions of var genes were also examined by circular dichroism $(\mathrm{CD})$,

Table 2: Sequence of the PQS from the var gene upstream B regions of $P$. falciparum

\begin{tabular}{ll}
\hline Name & Sequence \\
\hline UpsB-Q-1 & CAGGGTTAAGGGTATAACTTTAGGGGTTAGGGTT \\
UpsB-Q-2 & TAGGGTTAAGGGTATAACGTTAAGGGTTAGGGTT \\
UpsB-Q-3 & CAGGGTTAAGGGTATACATTTAGGGGTTAGGGTT \\
UpsB-Q-4 & CAGGGTTTAGGGTATAACTTTAGGGGTTAGGGTT
\end{tabular}

which provides information about the orientation of strands within a G-quadruplex, because the $\mathrm{CD}$ signal changes with the syn/anti orientation about the glycosylic bonds. In parallel G-quadruplexes, the CD spectrum typically exhibits a positive peak around $260 \mathrm{~nm}$ and a negative peak around $240 \mathrm{~nm}$, whereas in antiparallel Gquadruplexes, the $\mathrm{CD}$ spectrum displays a negative peak around $260 \mathrm{~nm}$ and a positive peak at $295 \mathrm{~nm}$ [39-41]. Results of CD for each UpsB-Q are showed in Figure 3. For UpsB-Q-2, 3 and 4 in potassium and ammonium, a minimum around $243 \mathrm{~nm}$ and a maximum around $295 \mathrm{~nm}$ were observed, while for UpsB-Q-1 in potassium the minimum was around $250 \mathrm{~nm}$. These kinds of spectra are generally attributed to hybrid conformations (containing a mixture of both parallel and antiparallel strand orientations). In sodium, the four sequences seem to adopt an antiparallel conformation, since a minimum near $260 \mathrm{~nm}$ and a maximum at $290-295 \mathrm{~nm}$ are observed. However, a shoulder was observed in the three cationic conditions at 270-275 nm for UpsB-Q-2, 3 and 4 but not for UpsB$\mathrm{Q}-1$. The absence of a shoulder in the case of UpsB-Q-1 could therefore indicate a different conformation of this G-quadruplex. Furthermore, the depth of the minimum observed for UpsB-Q-1 was systematically bigger than for the three other sequences. Together with NMR, this result suggests that the single structure adopted by UpsB-Q-1, the most frequent PQS in the UpsB regions, is different (probably closer to an antiparallel form) and that a few base mutations in UpsB-Q-1 (3 bases for UpsB-Q-2, 2 

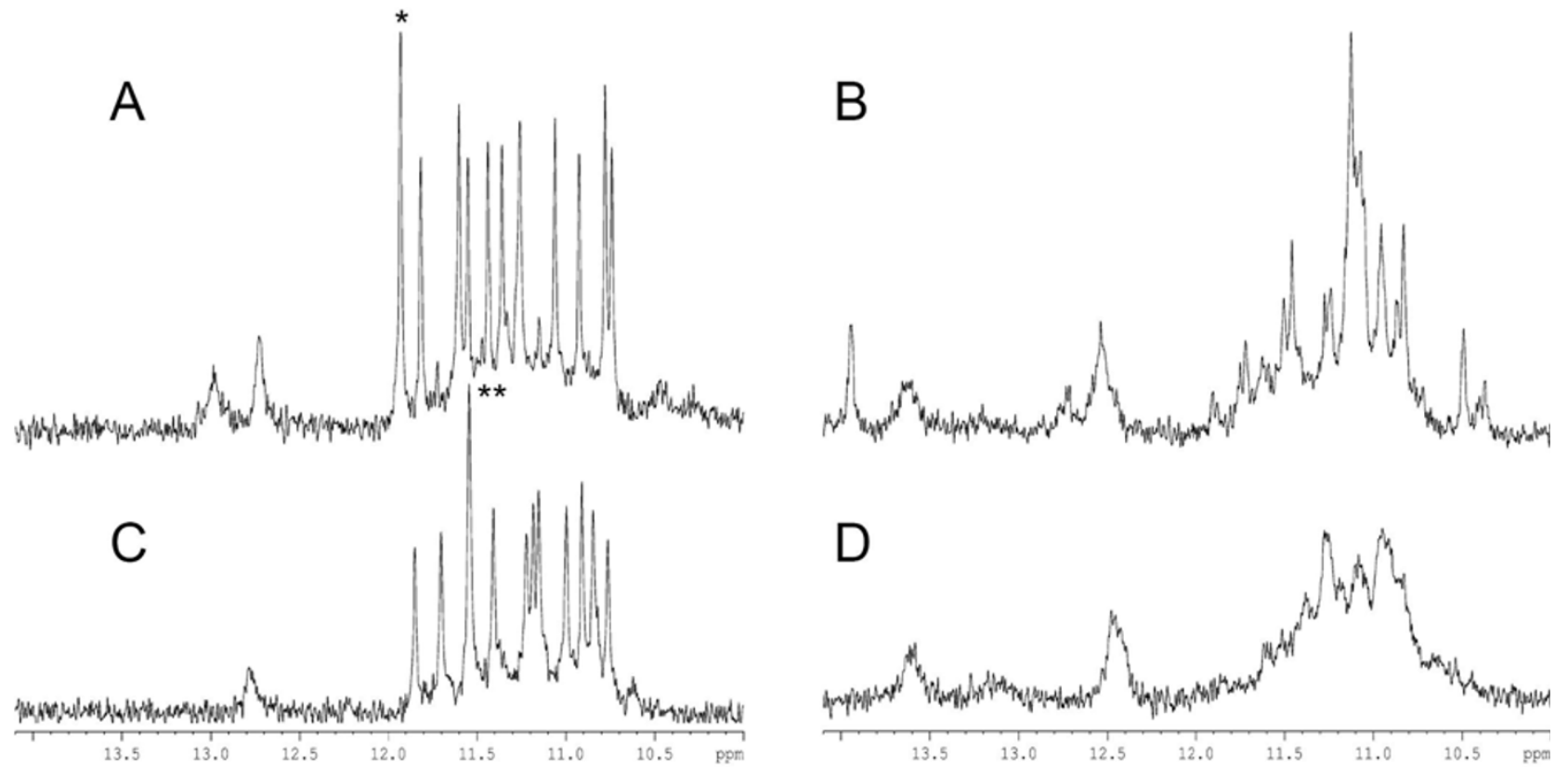

Figure 2

' $H$ NMR spectra of UpsB-Q-I in potassium (A) and ammonium (C) and of UpsB-Q-2 in potassium (B) and ammonium (D) (cation concentration $150 \mathrm{mM}$ ). These spectra were acquired at $25^{\circ} \mathrm{C}$. *: this peak was resolved in two peaks at $37^{\circ} \mathrm{C}$. **: due to its intensity, this peak most likely corresponds to the superposition of two peaks.

bases for UpsB-Q-3 and a single base for UpsB-Q-4) are sufficient to induce structural polymorphism.

Finally, thermal difference spectra (TDS) were recorded [42]. Similarly to $C D$, this technique differentiates between the various potential structures adopted by DNA. It was shown previously by Mergny et al [42] that G-quadruplexes exhibit two positive peaks at 243 and $273 \mathrm{~nm}$ and one negative peak at $295 \mathrm{~nm}$, while other DNA structures show different combinations of maxima and minima (see [42] for details of maxima and minima characterizing other DNA structures). The spectra obtained for the PQS from the var gene upstream $\mathrm{B}$ regions match expectations for G-quadruplex structures (Figure 4). There is a negative peak at $295 \mathrm{~nm}$ for all sequences in the three cations. Positive peaks were observed at 246 (only in
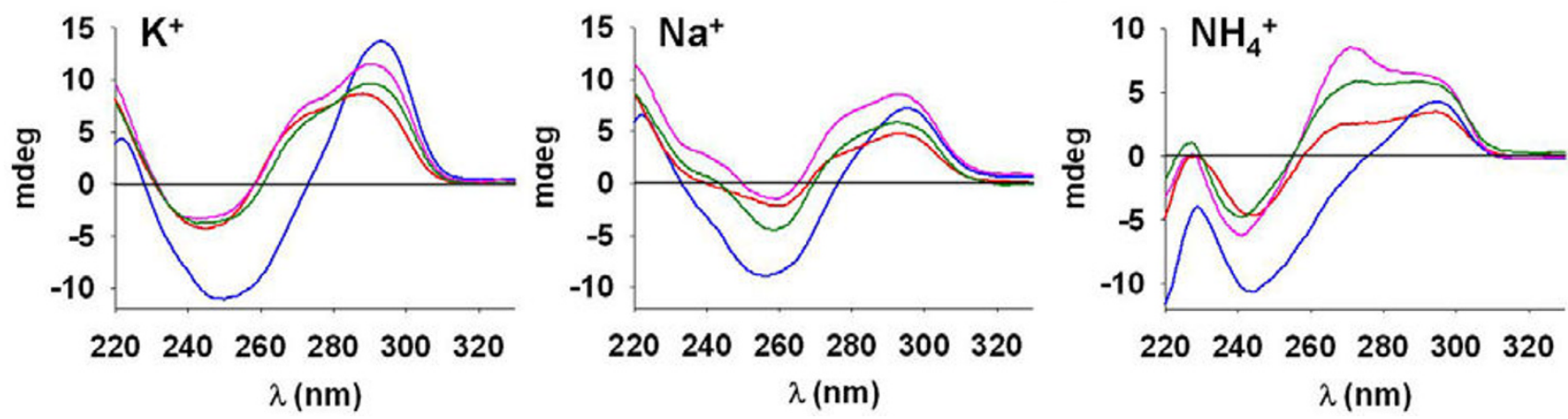

Figure 3

Circular dichroism spectra of putative G-quadruplex sequences (PQS) from the upstream B regions of var genes in $150 \mathrm{mM}$ potassium, sodium and ammonium cation. UpsB-Q-I (blue), UpsB-Q-2 (red), UpsB-Q-3 (pink) and UpsB-Q-4 (green). Characteristic signatures of hybrid G-quadruplexes (i.e. containing a mixture of parallel and antiparallel strand orientations) are observed in potassium and ammonium. In sodium, G-quadruplexes are predominantly antiparallel. 
potassium), 256 (except in ammonium) and $267 \mathrm{~nm}$. These values are in good agreement with previously described results [42] and thus confirm the ability of these sequences to form G-quadruplexes. There is a small wavelength shift for positive peaks, which may be because of the presence of a long loop (10 bases) in the PQS of the var gene upstream regions (all the G-quadruplexes previously tested contained no more than four bases in their loops).

The stoichiometries of the G-quadruplexes formed by the UpsB-Q were also examined to determine whether these structures are likely to form intra-molecular bonds (unimolecular structures) or inter-molecular bonds (multimolecular structures) [43]. Mass spectrometry showed only monomeric DNA (Additional file 3), indicating that the UpsB-Q form intra-molecular $G$ quadruplex structures (inter-molecular structures would have been indicated by the presence of multimers by mass spectrometry).

\section{Stability of G-quadruplexes formed by PQS in the upstreamB region of var genes}

When the UV absorbance is monitored at $295 \mathrm{~nm}$ [44], thermal denaturation experiments allow determination of the $T_{\mathrm{m}}$ of G-quadruplexes, i.e. the temperature at which the half of the signal is lost and thus indicate the relative stability of structures adopted by the oligonucleotides. Because G-quadruplexes with long loops are usually less stable that those with small loops $[43,45,46]$, it was necessary to check if the UpsB-Q are able to form G-quadruplexes that are stable under physiological conditions $\left(37^{\circ} \mathrm{C}\right.$ and $\left.\left[\mathrm{K}^{+}\right] \approx 150 \mathrm{mM}\right)$. These results are shown in Figure 4 and the $T_{\mathrm{m}}$ 's are listed in Table 3. In potassium, the four PQS sequences from the var gene upstream $\mathrm{B}$ regions have a $T_{\mathrm{m}}$ about $50^{\circ} \mathrm{C}$, and the transition curves (Figure 5) show that, at $37^{\circ} \mathrm{C}$, the proportion of folded Gquadruplexes is higher than $85 \%$ for the four sequences, confirming their potential to form G-quadruplexes in liv- ing cells. As expected, $T_{\mathrm{m}}$ 's observed in sodium and ammonium are lower than in potassium. This is generally attributed to the weaker stabilization capacity of these two cations, due to their smaller ionic radius [47-49]. The $T_{\mathrm{m}}$ ranking $\mathrm{K}^{+}>\mathrm{Na}^{+}>\mathrm{NH}_{4}{ }^{+}$is also characteristic of antiparallel G-quadruplexes (parallel G-quadruplexes have $T_{\mathrm{m}}$ ranking $\mathrm{K}^{+}>\mathrm{NH}_{4}^{+}>\mathrm{Na}^{+}$) [43].

\section{Interactions of UpsB-Q G-quadruplexes with a ligand}

In addition to the potential transcriptional repressor activity of G-quadruplex sequences themselves [27], it has been shown previously that G-quadruplex ligands can further suppress transcription of genes containing potential G-quadruplexes in their promoters, by impeding the binding of proteins needed for initiation of transcriptional activity on DNA [50,51]. Moreover, these molecules are also able to interfere with telomere structure and to indirectly induce their shortening [52-55]. These molecules are thus promising weapons in the fight against cancer, since this disease needs both a high expression of oncogenes and stable telomere length to develop and survive [56-62]. With the discovery of G-quadruplex forming sequences in the genome of $P$. falciparum, it can be hypothesized that these ligands may also have the potential to affect parasite gene expression by stabilizing Gquadruplexes located in gene promoter regions.

It was thus decided to evaluate the equilibrium dissociation constant of each UpsB-Q with the G-quadruplex ligand BOQ1 (Figure 6A). BOQ1 is a synthetic compound that exhibits a good selectivity for G-quadruplex versus duplex DNA $[63,64]$. A relatively high association constant with the UpsB-Q sequences would therefore provide additional evidence for the presence of G-quadruplex structures. Binding constants were determined by electrospray mass spectrometry. A typical spectrum of a G-quadruplex-ligand mixture is shown in Figure 6B. The peaks correspond to the free DNA sequence, and to $1: 1 \mathrm{com}$ -
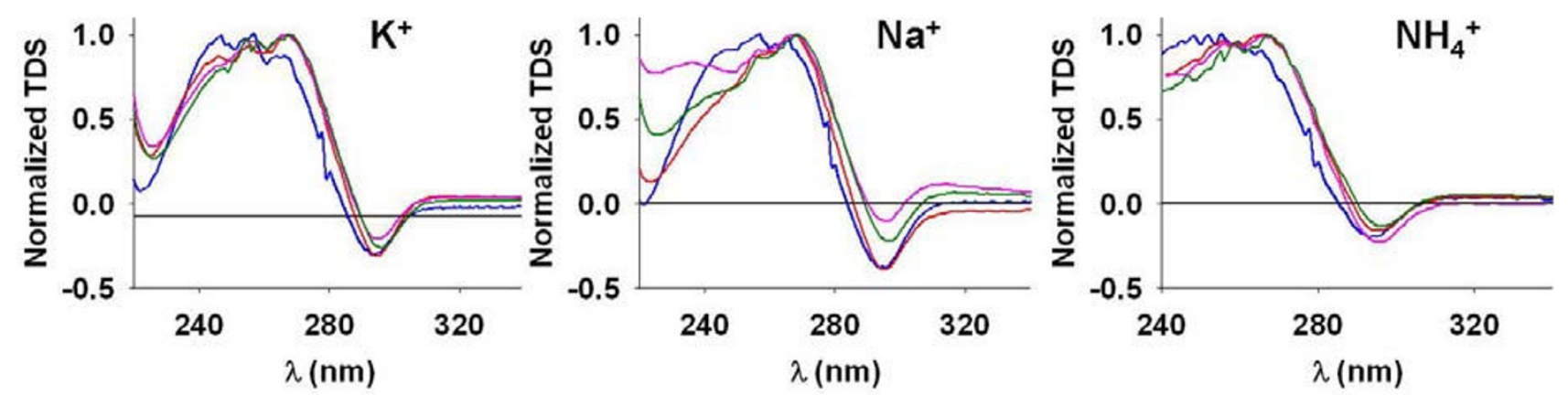

\section{Figure 4}

Thermal denaturation spectra of PQS from the upstream B regions of var genes in potassium, sodium and ammonium (cation concentration 150 mM). UpsB-Q-I (green), UpsB-Q-2 (blue), UpsB-Q-3 (red) and UpsB-Q-4 (pink). 


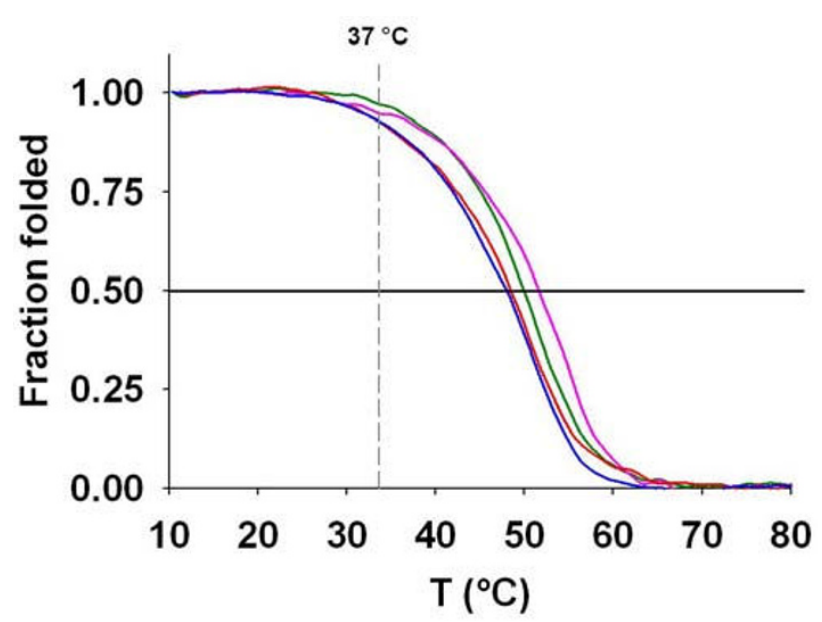

Figure 5

Thermal denaturation curves (heating) of putative G-quadruplex sequences (PQS) from the upstream B regions of var genes in $150 \mathrm{mM}$ potassium cation. UpsB-Q-I (blue), UpsB-Q-2 (red), UpsB-Q-3 (pink) and UpsB-Q-4 (green). For the four sequences, $T_{m}$ 's are about $50^{\circ} \mathrm{C}$ and the proportion of folded G-quadruplexes at $37^{\circ} \mathrm{C}$ is above $85 \%$.

plexes (1 ligand per DNA sequence), with charge states of 6-, 7- and 8-. The binding of a second ligand molecule was not observed, revealing that a single binding site is present.

The equilibrium dissociation constants of all UpsB-Q with BOQ 1 were deduced from the relative intensity of peaks of free DNA and complexes, as described previously [65]. For the four sequences, the values are around $2 \mu \mathrm{M}$ (Table 3). They are lower than those obtained by mass spectrometry for the binding of BOQ1 to telomeric Gquadruplex $(5.7 \mu \mathrm{M})$ or to model duplex sequences (57 $\mu \mathrm{M}$ ) (unpublished data). These results confirm the ability

Table 3: Melting temperature $\left(T_{m}\right)$ of G-quadruplex sequences from the upstream $B$ regions of var genes and the equilibrium dissociation constant of the PQS with the G-quadruplex ligand BOQ I (shown in the $K_{d}$ column)

\begin{tabular}{|c|c|c|c|c|}
\hline \multirow[b]{2}{*}{ PQS } & \multicolumn{3}{|c|}{$T_{m}{ }^{\prime}$} & \multirow[b]{2}{*}{$K_{d}(\mu M)$} \\
\hline & $\mathrm{K}^{+}$ & $\mathrm{Na}^{+}$ & $\mathrm{NH}_{4}{ }^{+}$ & \\
\hline UpsB-Q-I & $47.2 \pm 0.6$ & $35.1 \pm 1.2$ & $31.6 \pm 0.7$ & $2.6 \pm 0.5$ \\
\hline UpsB-Q-2 & $49 \pm 0.5$ & $36.1 \pm 2$ & $27.7 \pm 0.5$ & $1.4 \pm 0.4$ \\
\hline UpsB-Q-3 & $50 \pm 1.2$ & $36.9 \pm 1.1$ & $34.2 \pm 1.1$ & $1.7 \pm 0.7$ \\
\hline UpsB-Q-4 & $49.3 \pm 1.4$ & $39.4 \pm 0.9$ & $32.3 \pm 0.3$ & $2.7 \pm 1.1$ \\
\hline
\end{tabular}

I Thermal denaturation experiments were performed at the cation concentration of $150 \mathrm{mM}$. Thermal denaturation experiments were repeated twice and $T_{m}$ values shown are the mean of four values obtained from four curves (two heatings and two coolings). of the PQS in the upstream B regions of the var genes to fold in G-quadruplexes, and show that G-quadruplex ligands are likely to bind to these structures within the P. falciparum genome, and could therefore be tested for biological activity against the parasite.

\section{Potential for G-quadruplexes to be involved in gene transcriptional regulation in $P$. falciparum}

If the G-quadruplex structures in the P. falciparum genome can inhibit gene transcription in vivo, one would expect a mechanism to regulate these structures. It has been shown previously in vitro that some helicases specifically unwind G-quadruplexes in telomeres [66,67]. Two helicases of the conserved RecQ family, Sgs1p in yeast and BLM in human, show a much higher affinity for G-quadruplex than duplex DNA $[68,69]$. Moreover, a recent microarray study in a yeast mutant suggests that genes with a PQS in their upstream region tend to be downregulated when Sgs1p is knocked out [70]. The proposed explanation is that, in the absence of the helicase, G-quadruplexes in promoters cannot be unwound and they therefore act as a steric block to the transcriptional machinery [71]. A BLAST search with BLM and Sgs1p in P. falciparum brings up PFI0910w, annotated as a putative RecQ helicase on PlasmoDB. A ClustalW alignment with these 3 sequences shows that the 7 domains found in all RecQ helicases are also conserved in PFI0910w (Figure 7). PFI0910w is comparatively shorter and is lacking the RecQ-C-terminal and a HRDC (Helicase-and-RNaseD-like-C-terminal) domain present in BLM or Sgs1p. However, RecQ4, another human helicase part of the RecQ family, is also lacking these 2 domains [72]. Therefore it appears that P. falciparum does encode a helicase that may have the capacity to regulate G-quadruplex structures, allowing us to hypothesize that the RecQ helicase (PFI0910w) could be involved in UpsB var gene regulation. This suggestion that members of a particular var gene group could have a unique regulatory mechanism is not unprecedented, as it has been suggested previously that Group A and Evar gene transcription, but not groups $\mathrm{B}$ and $\mathrm{C}$ were influenced by the histone deacetylase Sir2 [11].

\section{Conclusion}

Increasing evidence suggests that G-quadruplexes play a role in gene transcriptional regulation in humans and other organisms. We identified 63 potential G-quadruplex sequences in the non-telomeric regions of the genome of P. falciparum clone 3D7. 16 of these PQS occurred in the upstream region of group $\mathrm{B}$ var genes. The var gene-related PQS were shown to form stable G-quadruplex structures in vitro under physiological conditions and bind with high affinity to a known G-quadruplex ligand. It is noteworthy that the most prevalent sequence UpsB-Q-1 (dCAGGGTTAAGGGTATAACTTTAGGGGTTAGGGTT) adopts a single structure which is stable in physiological conditions 


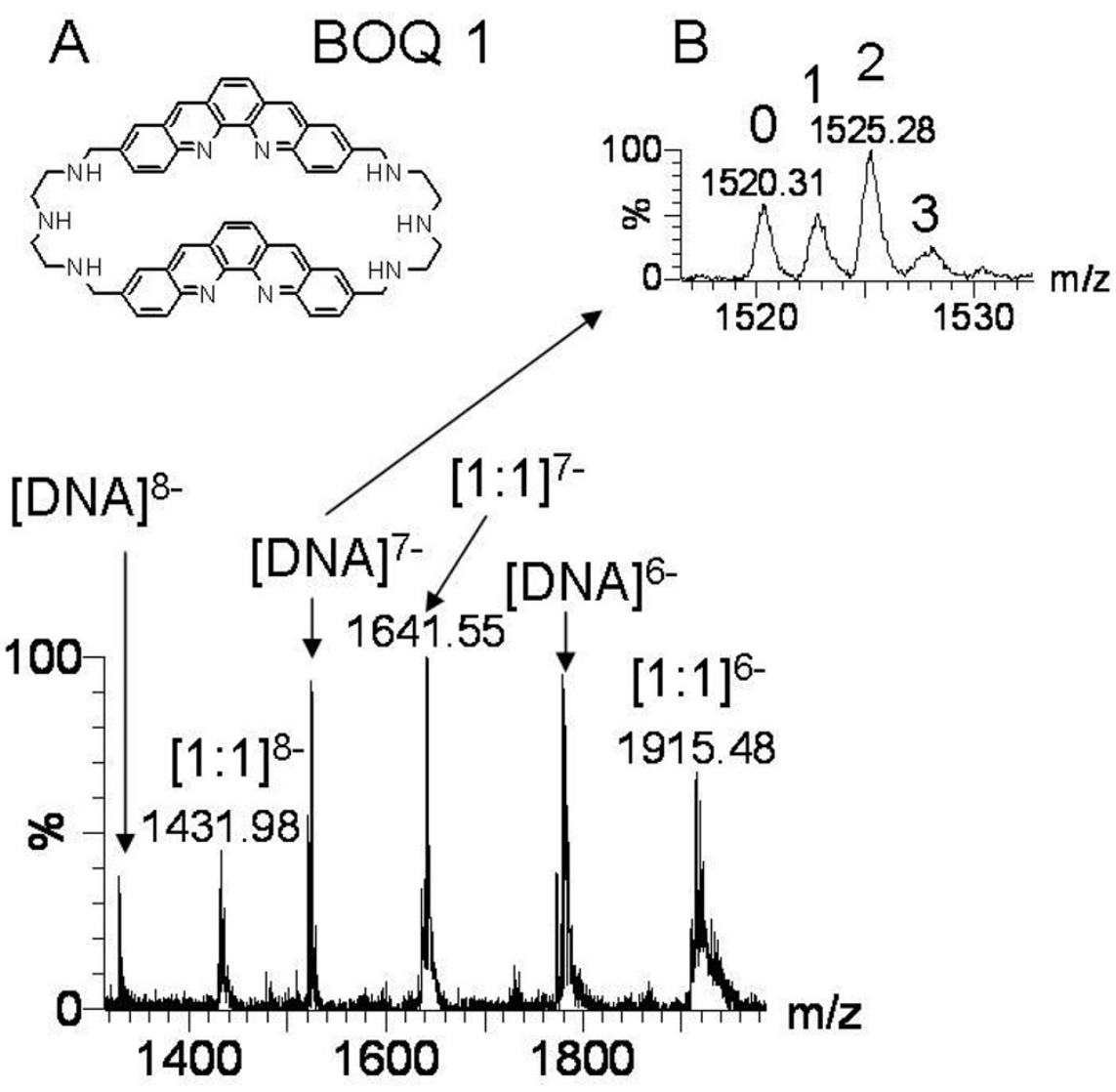

Figure 6

A: chemical structure of BOQ I. B: Mass spectrum of UpsB-Q-I and the G-quadruplex ligand BOQ I in equimolar concentrations $(10 \mu \mathrm{M})$. Only a [I:I] complex was observed. The upper panel shows a magnification on the DNA ${ }^{7-}$ and the number of ammonium adducts (from zero to three). The mass difference between two adjacent ammonium adducts is around 2.43 , indicating that the G-quadruplex is intramolecular.

$\left(37^{\circ} \mathrm{C}\right.$ and $\left.150 \mathrm{mM} \mathrm{K}\right)$. This discovery allows us to generate a new hypothesis concerning var gene regulation mechanisms in $P$. falciparum, in which a helicase such as PFI0910w could be involved in G-quadruplex unwinding and thus facilitate RNA polymerase transcriptional activity. The role of G-quadruplexes in Plasmodium gene regulation, the structure of these G-quadruplexes, and their use as potential drug targets merits further research.

\section{Methods}

\section{Bioinformatic analysis}

Both strands of each chromosome of the P. falciparum 3D7 clone (PlasmoDB_5.4 [73]) were analyzed using QGRS-Mapper [33]. The parameters used were: Max length: 33; Min G-group: 3; loop size: 0 to 11 . The P. falciparum HB3 genome was downloaded from the Broad Institute http://www.broad.mit.edu. Upstream sequences of var genes were analyzed using QGRS-Mapper with the same parameters.

\section{Materials}

All oligonucleotides were ordered from Eurogentec (Seraing, Belgium) with Oligold quality. The oligonucleotide sequences used are shown in the Table 2. Oligonucleotides were received lyophilized and stock solutions were prepared in bi-distilled water with $300 \mu \mathrm{M}$ total strand concentration. For all experiments, the stock solution was heated at $80^{\circ} \mathrm{C}$ for 5 minutes, diluted using a cold aqueous solution containing either $\mathrm{KCl}, \mathrm{NaCl}$ or $\mathrm{NH}_{4} \mathrm{OAc}$ to reach the desired DNA concentration in $150 \mathrm{mM}$ cation, and then cooled rapidly on ice. $10 \mathrm{mM}$ lithium cacodylate, $\mathrm{pH} 7.4$ was added in thermal denaturation and circular dichroism experiments. The molecule BOQ1 was synthesized as described previously [74] 


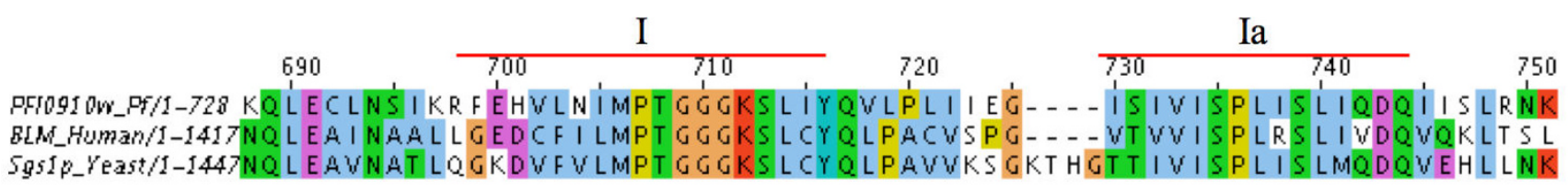

II

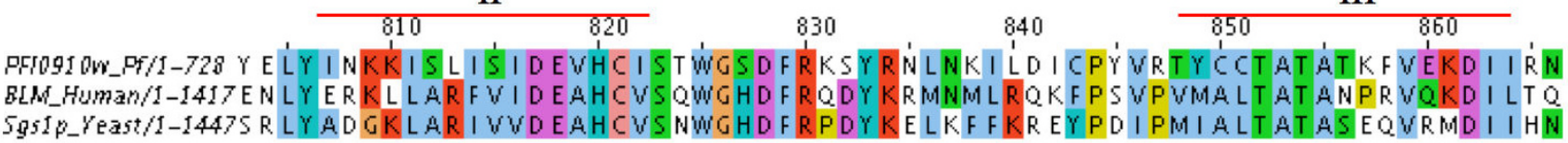

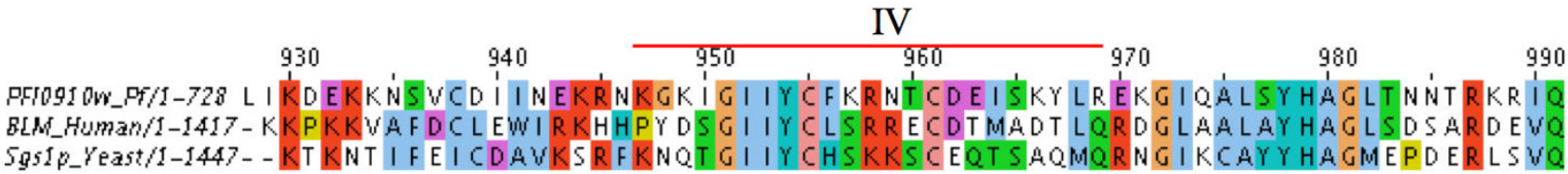

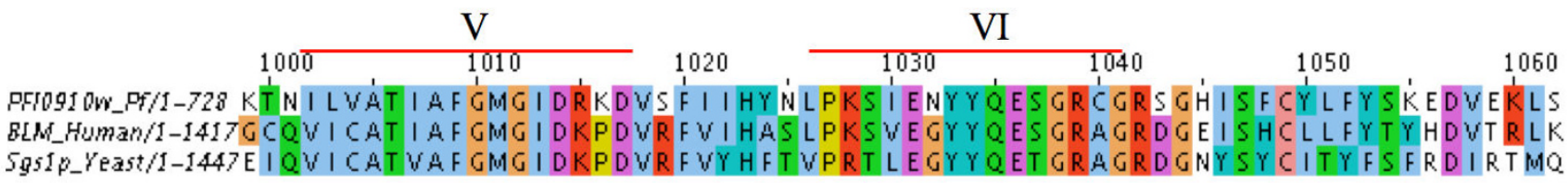

\section{Figure 7}

Alignment of PFI09 I Ow (P. falciparum) with two helicases of the RecQ family, BLM (human) and Sgs Ip (Saccharomyces cerevisiae). The seven conserved motifs of the helicase domain are indicated with a red bar.

\section{Circular dichroism}

Experiments were performed on a Jasco J-810 spectropolarimeter using 1-cm path length cells (Hellma, type No. 114-QS, France). The final concentration of oligonucleotide was $5 \mu \mathrm{M}$ in a buffer containing $150 \mathrm{mM}$ salt and 10 $\mathrm{mM}$ lithium cacodylate, $\mathrm{pH}$ 7.4. For each sample, five spectra were recorded from $220 \mathrm{~nm}$ to $350 \mathrm{~nm}$ with a scan rate of $100 \mathrm{~nm} / \mathrm{min}$.

\section{NMR}

NMR samples were prepared by dissolving the oligonucleotides in $\mathrm{H}_{2} \mathrm{O} / \mathrm{D}_{2} \mathrm{O} 90 / 10$, lithium cacodylate $10 \mathrm{mM}, \mathrm{pH}$ 7.4 to get a oligonucleotide final concentration of 270 $\mu \mathrm{M}$. Ammonium acetate or potassium chloride were progressively titrated in to a final cation concentration of 150 mM. NMR data were collected at $500 \mathrm{MHz}$ on a Bruker Avance spectrometer (fitted with a TXI triple resonance probe with $\mathrm{z}$-axis gradient). $1 \mathrm{D}{ }^{1} \mathrm{H}$ spectra were recorded at a temperature of $25^{\circ} \mathrm{C}$ using a WATERGATE sequence with a water flip-back pulse $[75,76]$.

\section{Thermal denaturation}

Thermal denaturation experiments were carried out on a Uvikon XS spectrophotometer (Secomam), using 1-cm path length quartz cells (Hellma, type No. 115B-QS, France). The final oligonucleotide concentration was 5 $\mu \mathrm{M}$ in $150 \mathrm{mM}$ salt and $10 \mathrm{mM}$ lithium cacodylate, $\mathrm{pH}=$ 7.4. Absorbance was monitored as a function of the tem- perature at 295,240, $260 \mathrm{~nm}$ for the determination of the melting temperature $\left(T_{\mathrm{m}}\right)[44]$ and at $405 \mathrm{~nm}$ as control wavelength. Gradient was $0.2^{\circ} \mathrm{C} / \mathrm{min}$ between 10 and $90^{\circ} \mathrm{C}$. Melting temperatures were determined using the method described by Marky and Breslauer [77]. Before heating and after the cooling, spectra were recorded from 220 to $440 \mathrm{~nm}$, to allow thermal difference spectra (TDS) to be obtained. TDS were obtained by subtracting the low temperature curve from the high temperature curve and normalization, as described previously by Mergny et al. [42].

\section{Electrospray mass spectrometry}

All measurements were carried out on a Q-TOF Ultima Global mass spectrometer (Micromass, now Waters, Manchester, U.K.), using the electrospray ionization (ESI) source in negative mode, as described previously [78]. Source conditions were optimized to avoid in-source fragmentation: capillary voltage $=-2.2 \mathrm{kV}$, cone voltage $=50$ $\mathrm{V}, \mathrm{RF}$, source block temperature $=80^{\circ} \mathrm{C}$, and desolvation gas temperature $=100^{\circ} \mathrm{C}$. Source backing pressure was set to $3.5 \mathrm{mbar}$. Oligonucleotide samples were first prepared at $50 \mu \mathrm{M}$ final concentration in $\mathrm{NH}_{4} \mathrm{OAc} 150 \mathrm{mM}$. Just before injection in the mass spectrometer, they were further diluted to $10 \mu \mathrm{M}$ in $150 \mathrm{mM} \mathrm{NH}_{4} \mathrm{OAc}$ and $20 \%$ methanol. The role of methanol is to increase ion signals. 


\section{Authors' contributions}

NS designed research, performed biophysical experiments, analyzed data and wrote the manuscript, AC designed research, performed the bioinformatics analysis, analyzed data and wrote the manuscript. CD performed NMR experiments and wrote the manuscript. FR contributed to biophysical experiments and analyzed data, EDP wrote the manuscript, MPTF contributed new reagent, JAR wrote the manuscript, VG analyzed data and wrote the manuscript. All authors read and approved the final manuscript.

\section{Additional material}

\section{Additional file 1}

Figure s1. Distribution of telomeric and non-telomeric Putative G-Quadruplex Sequences (PQS) in Plasmodium falciparum 3D7.

Click here for file

[http://www.biomedcentral.com/content/supplementary/1471-

2164-10-362-S1.doc]

\section{Additional file 2}

Figure s2 Full list of non-telomeric PQS in the Plasmodium falciparum $3 D 7$ genome.

Click here for file

[http://www.biomedcentral.com/content/supplementary/14712164-10-362-S2.xls]

\section{Additional file 3}

Supplementary Materials. Stoichiometry of G quadruplexes formed from the UpsB-Q.

Click here for file

[http://www.biomedcentral.com/content/supplementary/14712164-10-362-S3.doc]

\section{Acknowledgements}

We thank Prof. Pierre Colson for UV experiments, Dr Pascal De Tullio for NMR experiments and Dr. Andre Matagne for CD experiments. We acknowledge the FNRS and FRIA (VG is a FNRS research associate, FR is a FNRS postdoctoral researcher, and NS is a FRIA doctoral fellow) and the financial contributions of the Fonds de la Recherche Scientifique-FNRS (FRFC 2.4.623.05 to EDP; CC I.5.096.08 to VG) and the University of Liège (Starting Grant D-08/10 to VG). JAR is funded by a Wellcome Trust Senior Research Fellowship in Basic Biomedical Science (grant no. 06743I) and AC is funded by a Wellcome 4 year PhD studentship.

\section{References}

I. Snow RW, Guerra CA, Noor AM, Myint HY, Hay SI: The global distribution of clinical episodes of Plasmodium falciparum malaria. Nature 2005, 434:214-217.

2. Kyes SA, Kraemer SM, Smith JD: Antigenic variation in Plasmodium falciparum: gene organization and regulation of the var multigene family. Eukaryot Cell 2007, 6:15II-1520.

3. Lavstsen T, Salanti A, Jensen AT, Arnot DE, Theander TG: Subgrouping of Plasmodium falciparum 3D7 var genes based on sequence analysis of coding and non-coding regions. Malar J 2003, 2:27.

4. Kraemer SM, Kyes SA, Aggarwal G, Springer AL, Nelson SO, Christodoulou Z, Smith LM, Wang W, Levin E, Newbold Cl, et al.: Patterns of gene recombination shape var gene repertoires in
Plasmodium falciparum: comparisons of geographically diverse isolates. BMC Genomics 2007, 8:45.

5. Jensen AT, Magistrado P, Sharp S, Joergensen L, Lavstsen T, Chiucchiuini A, Salanti A, Vestergaard LS, Lusingu JP, Hermsen R, et al: Plasmodium falciparum associated with severe childhood malaria preferentially expresses PfEMPI encoded by group A var genes. J Exp Med 2004, 199: I I79-I 190.

6. Kyriacou HM, Stone GN, Challis RJ, Raza A, Lyke KE, Thera MA, Kone AK, Doumbo OK, Plowe CV, Rowe JA: Differential var gene transcription in Plasmodium falciparum isolates from patients with cerebral malaria compared to hyperparasitaemia. Mol Biochem Parasitol 2006, 150:21 I-2I8.

7. Kyes S, Christodoulou Z, Pinches R, Kriek N, Horrocks P, Newbold $C$ : Plasmodium falciparum var gene expression is developmentally controlled at the level of RNA polymerase II-mediated transcription initiation. Mol Microbiol 2007, 63: I237- 1247.

8. Dzikowski R, Frank M, Deitsch K: Mutually exclusive expression of virulence genes by malaria parasites is regulated independently of antigen production. PLoS Pathog 2006, 2:e22.

9. Voss TS, Kaestli M, Vogel D, Bopp S, Beck HP: Identification of nuclear proteins that interact differentially with Plasmodium falciparum var gene promoters. Mol Microbiol 2003, 48: $1593-1607$.

10. Voss TS, Tonkin CJ, Marty AJ, Thompson JK, Healer J, Crabb BS, Cowman AF: Alterations in local chromatin environment are involved in silencing and activation of subtelomeric var genes in Plasmodium falciparum. Mol Microbiol 2007, 66:139-150.

II. Duraisingh MT, Voss TS, Marty AJ, Duffy MF, Good RT, Thompson JK, Freitas-Junior LH, Scherf A, Crabb BS, Cowman AF: Heterochromatin silencing and locus repositioning linked to regulation of virulence genes in Plasmodium falciparum. Cell 2005, I 2 I: | 3-24.

12. Lopez-Rubio JJ, Gontijo AM, Nunes MC, Issar N, Hernandez Rivas R, Scherf A: 5 ' flanking region of var genes nucleate histone modification patterns linked to phenotypic inheritance of virulence traits in malaria parasites. Mol Microbiol 2007, 66:1296-1305.

13. Dzikowski R, Li F, Amulic B, Eisberg A, Frank M, Patel S, Wellems TE, Deitsch KW: Mechanisms underlying mutually exclusive expression of virulence genes by malaria parasites. EMBO Rep 2007, 8:959-965.

14. Simonsson T: G-quadruplex DNA structures - variations on a theme. Biol Chem 200I, 382:62I-628.

15. Macaya RF, Schultze P, Smith FW, Roe JA, Feigon J: Thrombin-binding DNA aptamer forms a unimolecular quadruplex structure in solution. Proc Natl Acad Sci USA 1993, 90:3745-3749.

16. Darby RA, Sollogoub M, McKeen C, Brown L, Risitano A, Brown N, Barton C, Brown T, Fox KR: High throughput measurement of duplex, triplex and quadruplex melting curves using molecular beacons and a LightCycler. Nucleic Acids Res 2002, 30(9):e39.

17. Huppert JL, Balasubramanian S: Prevalence of quadruplexes in the human genome. Nucleic Acids Res 2005, 33:2908-2916.

18. Todd AK, Johnston M, Neidle S: Highly prevalent putative quadruplex sequence motifs in human DNA. Nucleic Acids Res 2005 , 33:290I-2907.

19. Williamson JR, Raghuraman MK, Cech TR: Monovalent cationinduced structure of telomeric DNA: the G-quartet model. Cell 1989, 59:87I-880.

20. Nagesh N, Chatterji D: Ammonium ion at low concentration stabilizes the G-quadruplex formation by telomeric sequence. J Biochem Biophys Methods 1995, 30: I-8.

21. Chen FM: Sr2+ facilitates intermolecular G-quadruplex formation of telomeric sequences. Biochemistry 1992, 3I:3769-3776.

22. Pedroso IM, Duarte LF, Yanez G, Baker AM, Fletcher TM: Induction of parallel human telomeric G-quadruplex structures by Sr(2+). Biochem Biophys Res Commun 2007, 358:298-303.

23. Huppert JL, Balasubramanian S: G-quadruplexes in promoters throughout the human genome. Nucleic Acids Res 2007, 35:406-4I3

24. Sen D, Gilbert W: Formation of parallel four-stranded complexes by guanine-rich motifs in DNA and its implications for meiosis. Nature 1988, 334:364-366.

25. Henderson E, Hardin CC, Walk SK, Tinoco I Jr, Blackburn EH: Telomeric DNA oligonucleotides form novel intramolecular 
structures containing guanine-guanine base pairs. Cell 1987, $5 \mathrm{I}: 899-908$.

26. Murchie Al, Lilley DM: Retinoblastoma susceptibility genes contain 5 ' sequences with a high propensity to form guanine-tetrad structures. Nucleic Acids Res 1992, 20:49-53.

27. Siddiqui-Jain A, Grand CL, Bearss DJ, Hurley LH: Direct evidence for a G-quadruplex in a promoter region and its targeting with a small molecule to repress c-MYC transcription. Proc Natl Acad Sci USA 2002, 99: I I593-II598.

28. Rankin S, Reszka AP, Huppert J, Zloh M, Parkinson GN, Todd AK, Ladame S, Balasubramanian S, Neidle S: Putative DNA quadruplex formation within the human c-kit oncogene. J Am Chem Soc 2005, I 27:10584-10589.

29. Cogoi S, Xodo LE: G-quadruplex formation within the promoter of the KRAS proto-oncogene and its effect on transcription. Nucleic Acids Res 2006, 34:2536-2549.

30. Phan AT, Kuryavyi V, Burge S, Neidle S, Patel DJ: Structure of an Unprecedented G-Quadruplex Scaffold in the Human c-kit Promoter. J Am Chem Soc 2007, I 29:4386-4392.

31. Simonsson T, Pecinka P, Kubista M: DNA tetraplex formation in the control region of c-myc. Nucleic Acids Res 1998, 26: $1167-1172$

32. Maizels N: Dynamic roles for G4 DNA in the biology of eukaryotic cells. Nat Struct Mol Biol 2006, I3:1055-1059.

33. Kikin O, D'Antonio L, Bagga PS: QGRS Mapper: a web-based server for predicting G-quadruplexes in nucleotide sequences. Nucleic Acids Res 2006, 34:W676-682.

34. De Cian A, Grellier P, Mouray E, Depoix D, Bertrand H, Monchaud D, Teulade-Fichou MP, Mergny JL, Alberti P: Plasmodium Telomeric Sequences: Structure, Stability and Quadruplex Targeting by Small Compounds. Chembiochem 2008, 9:2730-2739.

35. Gardner MJ, Hall N, Fung E, White O, Berriman M, Hyman RW, Carlton JM, Pain A, Nelson KE, Bowman S, et al.: Genome sequence of the human malaria parasite Plasmodium falciparum. Nature 2002, 4 I 9:498-5II.

36. Phan AT, Patel DJ: Two-repeat human telomeric d(TAGGGTTAGGGT) sequence forms interconverting parallel and antiparallel G-quadruplexes in solution: distinct topologies, thermodynamic properties, and folding/unfolding kinetics. Am Chem Soc 2003, 125:15021-15027.

37. Phan AT, Modi YS, Patel DJ: Propeller-type parallel-stranded Gquadruplexes in the human c-myc promoter. J Am Chem Soc 2004, I 26:87| 0-87|6.

38. Ambrus A, Chen D, Dai J, Bialis T, Jones RA, Yang D: Human telomeric sequence forms a hybrid-type intramolecular G-quadruplex structure with mixed parallel/antiparallel strands in potassium solution. Nucleic Acids Res 2006, 34:2723-2735.

39. Balagurumoorthy P, Brahmachari SK, Mohanty D, Bansal M, Sasisekharan V: Hairpin and parallel quartet structures for telomeric sequences. Nucleic Acids Res 1992, 20:406 I-4067.

40. Balagurumoorthy P, Brahmachari SK: Structure and stability of human telomeric sequence. J Biol Chem 1994, 269:2 I 858-2 I869.

4I. Lu M, Guo Q, Kallenbach NR: Structure and stability of sodium and potassium complexes of dT4G4 and dT4G4T. Biochemistry | 1992, 3 I:2455-2459.

42. Mergny JL, Li J, Lacroix L, Amrane S, Chaires JB: Thermal difference spectra: a specific signature for nucleic acid structures. Nucleic Acids Res 2005, 33: el 38.

43. Smargiasso N, Rosu F, Hsia W, Colson P, Baker ES, Bowers MT, De Pauw E, Gabelica V: G-quadruplex DNA assemblies: loop length, cation identity, and multimer formation. J Am Chem Soc 2008, 130:10208-10216.

44. Mergny JL, Phan AT, Lacroix L: Following G-quartet formation by UV-spectroscopy. FEBS Lett 1998, 435:74-78.

45. Bugaut $A$, Balasubramanian S: $A$ sequence-independent study of the influence of short loop lengths on the stability and topology of intramolecular DNA G-quadruplexes. Biochemistry 2008, 47:689-697.

46. Hazel P, Huppert J, Balasubramanian S, Neidle S: Loop-lengthdependent folding of G-quadruplexes. I Am Chem Soc 2004 , 1 26: 16405-164I5.

47. Wlodarczyk A, Grzybowski P, Patkowski A, Dobek A: Effect of lons on the Polymorphism, Effective Charge, and Stability of Human Telomeric DNA. Photon Correlation Spectroscopy and Circular Dichroïsm Studies. J Phys Chem B 2005, 109:3594-3605.
48. Risitano A, Fox KR: Stability of intramolecular DNA quadruplexes: comparison with DNA duplexes. Biochemistry 2003, 42:6507-65I3.

49. Ross WS, Hardin CC: Ion-Induced Stabilization of the G-Dna Quadruplex - Free-Energy Perturbation Studies. J Am Chem Soc 1994, I 16:6070-6080.

50. Qin Y, Rezler EM, Gokhale V, Sun D, Hurley LH: Characterization of the G-quadruplexes in the duplex nuclease hypersensitive element of the PDGF-A promoter and modulation of PDGFA promoter activity by TMPyP4. Nucleic Acids Res 2007, 35:7698-77|3.

5I. Bejugam M, Sewitz S, Shirude PS, Rodriguez R, Shahid R, Balasubramanian S: Trisubstituted Isoalloxazines as a New Class of G. Quadruplex Binding Ligands: Small Molecule Regulation of c-kit Oncogene Expression. I Am Chem Soc 2007, I 29: I 2926-I 2927.

52. Zhou JM, Zhu XF, Lu YJ, Deng R, Huang ZS, Mei YP, Wang Y, Huang WL, Liu ZC, Gu LQ, et al.: Senescence and telomere shortening induced by novel potent $G$-quadruplex interactive agents, quindoline derivatives, in human cancer cell lines. Oncogene 2006, 25:503-5II.

53. Tahara H, Shin-Ya K, Seimiya H, Yamada H, Tsuruo T, Ide T: GQuadruplex stabilization by telomestatin induces TRF2 protein dissociation from telomeres and anaphase bridge formation accompanied by loss of the 3' telomeric overhang in cancer cells. Oncogene 2006, 25:1955-1966.

54. Phatak P, Cookson JC, Dai F, Smith V, Gartenhaus RB, Stevens MF, Burger AM: Telomere uncapping by the G-quadruplex ligand RHPS4 inhibits clonogenic tumour cell growth in vitro and in vivo consistent with a cancer stem cell targeting mechanism. $\mathrm{Br}$ J Cancer 2007, 96: 1223-1233.

55. Riou JF: G-quadruplex interacting agents targeting the telomeric G-overhang are more than simple telomerase inhibitors. Curr Med Chem Anti-Canc Agents 2004, 4:439-443.

56. Patel DJ, Phan AT, Kuryavyi V: Human telomere, oncogenic promoter and 5'-UTR G-quadruplexes: diverse higher order DNA and RNA targets for cancer therapeutics. Nucleic Acids Res 2007, 35:7429-7455.

57. Pagano B, Giancola C: Energetics of quadruplex-drug recognition in anticancer therapy. Curr Cancer Drug Targets 2007, 7:520-540.

58. Han H, Hurley LH: G-quadruplex DNA: a potential target for anti-cancer drug design. Trends Pharmacol Sci 2000, 2I: I 36-I 42

59. Incles CM, Schultes CM, Kempski H, Koehler H, Kelland LR, Neidle S: A G-quadruplex telomere targeting agent produces pl6associated senescence and chromosomal fusions in human prostate cancer cells. Mol Cancer Ther 2004, 3: I20I-1206.

60. Izbicka E, Wheelhouse RT, Raymond E, Davidson KK, Lawrence RA Sun D, Windle BE, Hurley LH, Von Hoff DD: Effects of cationic porphyrins as G-quadruplex interactive agents in human tumor cells. Cancer Res 1999, 59:639-644.

6I. Cookson JC, Dai F, Smith V, Heald RA, Laughton CA, Stevens MF, Burger AM: Pharmacodynamics of the G-Quadruplex-Stabilizing Telomerase Inhibitor 3, II-Difluoro-6,8, 13-trimethyl8H-quino[4,3,2-kl]acridinium methosulfate (RHPS4) in Vitro: Activity in Human Tumor Cells Correlates with Telomere Length and Can Be Enhanced, or Antagonized, with Cytotoxic Agents. Mol Pharmacol 2005, 68: I55I-I558.

62. Burger AM, Dai F, Schultes CM, Reszka AP, Moore MJ, Double JA Neidle S: The G-quadruplex-interactive molecule BRACO-19 inhibits tumor growth, consistent with telomere targeting and interference with telomerase function. Cancer Res 2005 , 65: $1489-1496$.

63. Gabelica V, Baker ES, Teulade-Fichou MP, De Pauw E, Bowers MT: Stabilization and structure of telomeric and c-myc region intramolecular G-quadruplexes: the role of central cations and small planar ligands. J Am Chem Soc 2007, I 29:895-904 .

64. Teulade-Fichou MP, Carrasco C, Guittat L, Bailly C, Alberti P, Mergny J-L, David A, Lehn J-M, Wilson WD: Selective Recognition of GQuadruplex Telomeric DNA by a Bis(quinacridine) Macrocycle. J Am Chem Soc 2003, I 25:4732-4740.

65. Rosu F, De Pauw E, Guittat L, Alberti P, Lacroix L, Mailliet P, Riou JF, Mergny JL: Selective interaction of ethidium derivatives with quadruplexes: an equilibrium dialysis and electrospray ionization mass spectrometry analysis. Biochemistry 2003, 42: $1036|-1037|$. 
66. Zaug AJ, Podell ER, Cech TR: Human POTI disrupts telomeric G-quadruplexes allowing telomerase extension in vitro. Proc Natl Acad Sci USA 2005, I 02: 10864-10869.

67. Nakagama H, Higuchi K, Tanaka E, Tsuchiya N, Nakashima K, Katahira $M$, Fukuda $\mathrm{H}$ : Molecular mechanisms for maintenance of Grich short tandem repeats capable of adopting G4 DNA structures. Mutat Res 2006, 598:120-131.

68. Sun H, Bennett RJ, Maizels N: The Saccharomyces cerevisiae Sgs I helicase efficiently unwinds G-G paired DNAs. Nucleic Acids Res 1999, 27:1978-1984.

69. Sun H, Karow JK, Hickson ID, Maizels N: The Bloom's syndrome helicase unwinds G4 DNA. I Biol Chem I 998, 273:27587-27592.

70. Hershman SG, Chen Q, Lee JY, Kozak ML, Yue P, Wang LS, Johnson FB: Genomic distribution and functional analyses of potential G-quadruplex-forming sequences in Saccharomyces cerevisiae. Nucleic Acids Res 2008, 36: I44- 156.

7I. Huppert JL: Hunting G-quadruplexes. Biochimie 2008, 90: II $140-1 \mid 48$

72. Killoran MP, Keck JL: Sit down, relax and unwind: structural insights into RecQ helicase mechanisms. Nucleic Acids Res 2006, 34:4098-4105.

73. Aurrecoechea C, Brestelli J, Brunk BP, Dommer J, Fischer S, Gajria B, Gao X, Gingle A, Grant G, Harb OS, et al.: PlasmoDB: a functional genomic database for malaria parasites. Nucleic Acids Res 2008 , 37:D539-543.

74. Baudoin O, Teulade-Fichou MP, Vigneron JP, Lehn JM: Cyclobisintercaland Macrocycles: Synthesis and Physicochemical Properties of Macrocyclic Polyamines Containing Two CrescentShaped Dibenzophenanthroline Subunits. J Org Chem 1997, 62:5458-5470.

75. Piotto M, Saudek V, Sklenar V: Gradient-tailored excitation for single-quantum NMR spectroscopy of aqueous solutions. J Biomol NMR 1992, 2:661-665.

76. Sklenar V, Piotto M, Leppik R, Saudek V: Gradient-Tailored Water Suppression for H-I-N-I5 Hsqc Experiments Optimized to Retain Full Sensitivity. Journal of Magnetic Resonance Series A 1993, 102:24I-245.

77. Marky LA, Breslauer KJ: Calculating thermodynamic data for transitions of any molecularity from equilibrium melting curves. Biopolymers 1987, 26:160I-1620.

78. Rosu F, Gabelica V, Houssier C, Colson P, Pauw ED: Triplex and quadruplex DNA structures studied by electrospray mass spectrometry. Rapid Commun Mass Spectrom 2002, I 6:I729-I 736.
Publish with Biomed Central and every scientist can read your work free of charge

"BioMed Central will be the most significant development for disseminating the results of biomedical research in our lifetime. "

Sir Paul Nurse, Cancer Research UK

Your research papers will be:

- available free of charge to the entire biomedical community

- peer reviewed and published immediately upon acceptance

- cited in PubMed and archived on PubMed Central

- yours - you keep the copyright

Submit your manuscript here:

http://www.biomedcentral.com/info/publishing_adv.asp
BioMedcentral 